\title{
The emerging therapeutic role of some pharmacological antidotes in management of COVID-19
}

\author{
Doaa M. El Shehaby', Marwa Kh. Mohammed', Noha Esmael Ebrahem¹, Mariam M. Abd El-Azim', \\ Islam G. Sayed ${ }^{2^{*}}$ (1) and Sarah A. Eweda ${ }^{3}$
}

\begin{abstract}
Background: A novel RNA coronavirus was identified in January 2020 as the cause of a pneumonia epidemic affecting the city of Wuhan; it rapidly spread across China.

Aim of the review: The aim is to discuss the potential efficacy of some pharmacologically known pharmacological antidotes (N-acetylcysteine; hyperbaric oxygen; deferoxamine; low-dose naloxone) for the management of COVID19-associated symptoms and complications.

Method: An extensive search was accomplished in Medline, Embase, Scopus, Web of Science, and Central databases until the end of April, 2021. Four independent researchers completed the screening, and finally, the associated studies were involved.

Conclusion: The current proof hinders the experts for suggesting the proper pharmacological lines of treatment of COVID-19. Organizations, for example, WHO, should pursue more practical actions and design well-planned clinical trials so that their results may be used in the treatment of future outbreaks.
\end{abstract}

Keywords: COVID-19, NAC, HBO, Deferoxamine, LDN

\section{Introduction}

Early in January 2020, a novel RNA coronavirus was identified as the cause of a pneumonia epidemic affecting Wuhan, spreading rapidly across China, then across the world, with the quickly increasing every day number of established new cases [1-3]. Up to 28 March 2020, the death of 26,495 individuals worldwide and infection of more than 570,000 were caused by COVID-19 [4].

The World Health Organization (WHO) named coronavirus disease 2019 as COVID-19. It has been declared as a pandemic because of its widespread infectivity and highly contagious rate. Respiratory and enteric infections are the typical presentation of the human coronaviruses

\footnotetext{
*Correspondence: islamgalal@aswu.edu.eg

${ }^{2}$ Chest Department, Faculty of Medicine, Aswan University, Aswan, Egypt Full list of author information is available at the end of the article
}

$[5,6]$. The main presentation of infection with COVID-19 is the flu-like symptoms such as fever, cough, and asthenia, resembling other coronaviruses $[7,8]$. Severe lung injury has been pronounced at all ages, which can precipitate acute respiratory failure with high fatality rates. The virus is more probable to cause severe manifestations in some high-risk individuals, such as the elderly or those affected by multiple previous morbidities, these in the form of acute respiratory distress syndrome, interstitial pneumonia, and subsequent multi-organ failure [9].

COVID-19 is mainly a disease with respiratory manifestations, but it is important for clinicians to be aware of the increasing reports of thrombotic and cardiovascular complications which are recognized during infection with COVID-19. The proinflammatory immune response with high levels of inflammatory processes which is 
present in most infected cases is associated with hypercoagulable state [10].

Management of the infected cases is mainly symptomatic and supportive [11-14]. Most available therapeutic options for managing COVID-19 are based on the experiences regarding treatment of SARS-CoV and MERS$\mathrm{CoV}$. The WHO guidelines of treatment of infected cases are supportive care including oxygen therapy in addition to fluid therapy and antibiotics for treating secondary infections, with social isolation of the confirmed and suspected patients for COVID-19 [15].

The purpose of the present mini-review is to discuss the potential efficiency of some pharmacologically known antidotes in alleviating the clinical manifestations of COVID-19 contagion with a brief discussion of their mechanisms to counteract the symptoms of COVID-19 infection.

\section{Main text \\ Methodology}

Two groups of investigators were working independently for the study selection. A search was performed using the following databases: Science Direct, PubMed, Scopus, Medline, Google Scholar, and Web of Science. Any discrepancies were resolved through consensus. All articles which were supposed potentially authorized were retrieved for full-text reviews. We limited our search results to publications in English and excluded abstracts from conferences and observations. The keyword "coronavirus" was paired with coronavirus and/ or COVID-19 was paired with one or more of "ARDS," "N acetyl cysteine," "hyperbaric oxygen," "deferoxamine," "low dose naloxone," and "methylene blue" to obtain published articles up till October 2020. No language restraint was imposed.

\section{Discussion}

The COVID-19 pandemic is caused by the coronavirus 2 (SARS-CoV-2) that belongs to the Coronaviridae family. This family has been accountable for two viral epidemics recently; the first one was during 2003 due to severe acute respiratory syndrome coronavirus (SARS) [16]. The second outbreak was during 2012 due to the spread of coronavirus (MERS-CoV) [17].

Recently, severe acute respiratory syndrome (SARSCoV-2), a novel strain of fatal coronavirus, struck China mainly in Wuhan. It is a beta type of coronaviruses proposed with the name (family: Coronaviridae). This novel strain of coronavirus managed to spread within a very short period of time over a wide geographic location. On February 28, 2020, the total number of confirmed nCoV19 infections worldwide was 83,652 , and the number of deaths is more than 3000 [18].
Coronaviruses $(\mathrm{CoV})$ are enveloped viruses that contain non-segmented, positive-stranded genomic RNA [19]. These viruses are characterized by being pleomorphic particles, sized from 80 up to $120 \mathrm{~nm}$, and their replication cycle entirely occurs in the cytoplasm [20]. An innovative coronavirus 2019 (nCoV-19) has been recently identified in humans that was responsible for thousands of deaths during the period from January to March 2020 [21]. Furthermore, CoVs were established to be the causal of the Middle East respiratory syndrome (MERS-CoV) and SARS-CoV-2. Serologically, there are three strains of this virus that have been reported up to date. Two strains which are $\mathrm{HCoV}-229 \mathrm{E}$ and $\mathrm{HCoV}$ OC43 have been identified in 1960 causing the well-controlled common cold symptoms. The third coronavirus that is life-threatening and may lead to lethal pneumonia is called SARS-CoV [22].

COVID-19 virus transmission can occur primarily direct through contact with the diseased cases or indirect through contact with objects used by the infected people $[5,6,23]$. Respiratory contagions can be occur through droplets of diverse sizes (droplet particles; sized $>5-10 \mu \mathrm{m}$ and droplet nuclei; sized $<5 \mu \mathrm{m}$ ) [24]. Studies on cultured COVID-19 virus from a stool specimen revealed its feco-oral transmission [25, 26].

The sequence of the virus life within the host consists of 5 stages: attachment, penetration, biosynthesis, then maturation and lastly release. At first (attachment) is the binding of the viruses to the host receptors, entering host cells through membrane fusion (penetration) or endocytosis. Immediately when the viral contents were released inside the host cells, the viral RNA enters the nucleus for replication. Viral mRNA is used to make viral proteins (biosynthesis). Finally, the novel viral particles are designed (maturation) and released [27].

\section{Therapeutic management of COVID-19}

Presently, there is no evidence from randomized clinical trials (RCTs) that any potential therapy improves outcomes in patients with either suspected or confirmed COVID-19. There are no clinical trial data supporting any prophylactic treatment. More than 3 hundred vigorous clinical treatment trials are in progress [28].

The treatment protocols for severe cases of SARS include supportive care with mechanical ventilation and ICU admission [29], depending on the hypothesis of cytokine deregulation, and treatment guidelines including the administration of steroids, aiming to modulate the exacerbated cytokine response [30].

Recent guidelines establish the usage of some antibacterial drugs for prevention of secondary bacterial contagions and steroids for modulation of cytokine deregulation in addition to ribavirin which is a nucleoside 
analog with a broad antiviral activity [25, 26]. Several challenges were made to study in vitro susceptibility to various complexes with potential anti-SARS activity.

\section{Hyperbaric oxygen therapy}

Hyperbaric oxygen therapy (HBOT) is the primary antidotal therapy for acute carbon monoxide toxicity. It is a sort of management considered to increase the oxygen level in the blood delivered to the tissues. It is defined as breathing of $100 \%$ oxygen at elevated atmospheric pressure than the sea-level. The pressure applied usually is 2 to 3 times the atmospheric pressure at sea level [31]. It can be delivered either in a mono-place or a multi-place chamber. Mono-place chambers are condensed with pure oxygen accepting single case at one time, while multiplace chambers are pressurized with air accommodating multiple cases that can breathe throughout a tight-fitting face or endotracheal tube as clinically indicated. Management generally lasts for up to $8 \mathrm{~h}$, depending on the indication, and may be accomplished 1 to 3 times on a daily basis [32].

Presently, there are numerous FDA accepted circumstances for the practice of HBOT in clinical toxicology as carbon monoxide poisoning, as well as gas and air embolism, clostridial myositis, crush injury, compartment syndrome, decompression sickness, diabetic foot, and chronic intractable osteomyelitis [33].

Therapeutic mechanisms of action of HBOT are established on Henry's Law, which declares that the concentration of an interfacing gas (oxygen in the alveoli of the lungs) in a liquid (pulmonary blood) is comparative to the interfacing gas pressure. The final oxygen uptake and binding to the hemoglobin in red blood cells of the pulmonary capillary are reliant on the diffusion of dissolved oxygen across alveolar-capillary membrane to blood flow [34].

Hyperbaric oxygen therapy produces the rise of both the hydrostatic pressure and the partial pressure of oxygen during which the arterial oxygen tension classically exceeds $1500 \mathrm{~mm} \mathrm{Hg}$, consequently rising the dissolved oxygen content of plasma over the required to meet the cellular resting requirements without any involvement from the hemoglobin binding oxygen [32].

Rationale of hyperbaric oxygen therapy in management of COVID-19 Progressive hypoxemia is a characteristic sign in the clinical course of severe COVID-19 pneumonia. The latest data suggest that interstitial and alveolar inflammation amid the thickened alveolar-capillary membrane was the major pathological alteration in COVID-19 pneumonia [35, 36]. Moreover, systemic metabolic rate was found to be continuously rising owing to the systemic inflammation, so the amount of oxygen transported by hemoglobin cannot meet the body's metabolic needs. The body is in a "chronic" hypoxic state of systemic tissues; therefore, in some patients, the extracorporeal membrane oxygenation may still be insufficient to correct hypoxia in deep tissues and vital organs $[37,38]$.

Several studies suggest certain proteins of the novel virus could attack the 1-beta chain of hemoglobin, consequently dissociating iron from porphyrin resulting in destruction of the hemoglobin as a cause of hypoxemia in COVID-19. This attack would result in a drop in the hemoglobin available to carry oxygen and also shift the oxygen dissociation curve to the left hence producing a picture comparable to carbon monoxide poisoning [39].

The application of HBOT to pneumonia cases due to COVID-19 is of great effectiveness through the various following mechanisms:

1. It enhances multiple stages of oxygen diffusion by increasing the dissolved oxygen in the alveolar and inflammatory barriers with subsequent increasing the amount of oxygen dissolved in blood plasma, so raising the oxygen saturation of hemoglobin in red blood cells. Thus, it delivers satisfactory blood oxygen levels virtually in comprehensive absence of lung-blood exchange [40]. Moreover, it solves the imbalance between oxygen prerequisite and oxygen available through providing the body with an intermission of adequate aerobic metabolism for the deep hypoxic tissues and important organs playing a good role in supporting treatment [41].

2. It has a definite immunosuppressive effect; it can reduce the intensity of the inflammatory response to stimulus-induced pro-inflammatory cytokine construction. It encourages cytokine downregulation, decreasing IL-1, IL-6, and TNFo levels [42]. The immunosuppressive outcome of HBOT might be owing to variations in the distribution of mononuclear cells and macrophage function impairment which is a significant origin of IL- 1 and TNF $\alpha$. Furthermore, HBOT was instituted to persuade apoptosis in other cytokine-producing cells reducing cytokine manufacture [43]. The immunosuppression of the pro-inflammatory interleukins IL- 1 and IL- 6 have beneficial effects in various inflammatory disorders including viral contagions [11, 12, 44]. HBOT declines TLR expression, NF-kB signaling trails, and the expression of these molecular platforms in diverse tissues $[45,46]$.

3. It has several bactericidal, bacteriostatic effects, suppresses toxin production, or strengthens resistance against contagions. HBOT inhibits the adherence of 
neutrophils to the endothelium of vessels, reducing inflammation, free radicals manufacture, vasoconstriction, and tissue destruction $[47,48]$.

4. It can noticeably prevent the variation in the coagulation cascade in an experimental model of multiple organ failure syndrome. In a study done by Imperatore et al. [49], they explained that HBOT could reduce the stimulation of the coagulation system, the inhibition of fibrinolysis, and platelet hyper-aggregation.

5. It has a great beneficial role in the management of various thrombotic events as cerebral thrombosis since it relieves brain edema by its vasoconstriction action and counteracts the vasodilatation of the capillaries in the hypoxic tissues decreasing the permeability of $\mathrm{BBB}$. $\mathrm{HBO}$ also reduces the swelling of the neurons by improving their metabolism [50]. COVID-19 may persuade to both venous and arterial embolisms owing to excessive inflammation along with hypoxia, immobilization, and diffuse intravascular coagulation [51].

A recent systematic review summarized that overall, HBOT seems to be a safe and effective method of oxygenation in patients with COVID-19. However, its large space occupation and lack of availability in large numbers may limit its use in the settings of a pandemic where many patients require oxygenation, and this shortcoming needs to be addressed. There is limited knowledge and evidence regarding the effects of HBOT in the settings of COVID-19, and further well-designed trials with larger sample sizes are recommended to carefully assess the outcomes of this treatment modality and compare it with other oxygenation methods [52].

Management protocol of HBOT in COVID-19 according to the recent recommendations summarized that HBOT is indicated in confirmed COVID-19 patient with $\mathrm{SO}_{2}$ saturation $\leq 90 \%$, with signs of hypoxemia or pulmonary hypoxia provided no respiratory distress, pulmonary shock, emphysema, air cysts, or bullae, and untreated pneumothorax. The treatment protocol is carried out with 1.45 atmospheric pressure sessions of $120 \mathrm{~min}$, once per day. The patient and the operator must have all the equipment required for personal safety and isolation. Regular evaluation of oxygen saturation is essential; CT chest and ultrasound are obligatory to evaluate the clinical response to treatment after the 5th session [53].

There may also many side effects of HBOT such as middle ear barotrauma (MEB), sinus/paranasal barotrauma, dental barotrauma, central nervous system (CNS) oxygen toxicity, pulmonary oxygen toxicity, hyperoxic myopia, cataracts, retrolental fibroplasia following hyperoxic exposure, claustrophobia or increase in blood pressure, pulmonary edema, and hypoglycemia in diabetics [54]. Furthermore, oxygen toxicity due to excess free radical generation, barotrauma to the middle ear, pneumothorax, and inert gas uptake induced narcosis are the commonly reported complications of HBOT.

\section{$\mathrm{N}$-acetyl cysteine (NAC)}

It is an antidote of paracetamol overdose; it is an acetylated precursor of L-cysteine amino acid where acetyl group attached to the nitrogen atom. It has been also approved in the management of various disorders involving; doxorubicin cardiotoxicity, ischemia-reperfusion cardiac injury, bronchitis, acute respiratory distress syndrome (ARDS), HIV/AIDS, and psychiatric disorders [55] (Fig. 1).

The World Health Organization recognizes NAC as a pertinent and a significant medication required in a very basic health system. It may be administered orally or intravenously or in a nebulizer form as in cases of acute lung diseases [56]. It has numerous advantages: as is considered a stable drug, commercially available at a low price and a safe drug with low bioavailability [57].

\section{Mechanism of action}

NAC has shown mucolytic, antioxidant, and anti-inflammatory properties.

\section{Mucolytic effect}

It has a mucolytic effect by breaking the disulfide bridges between macromolecules of mucous and

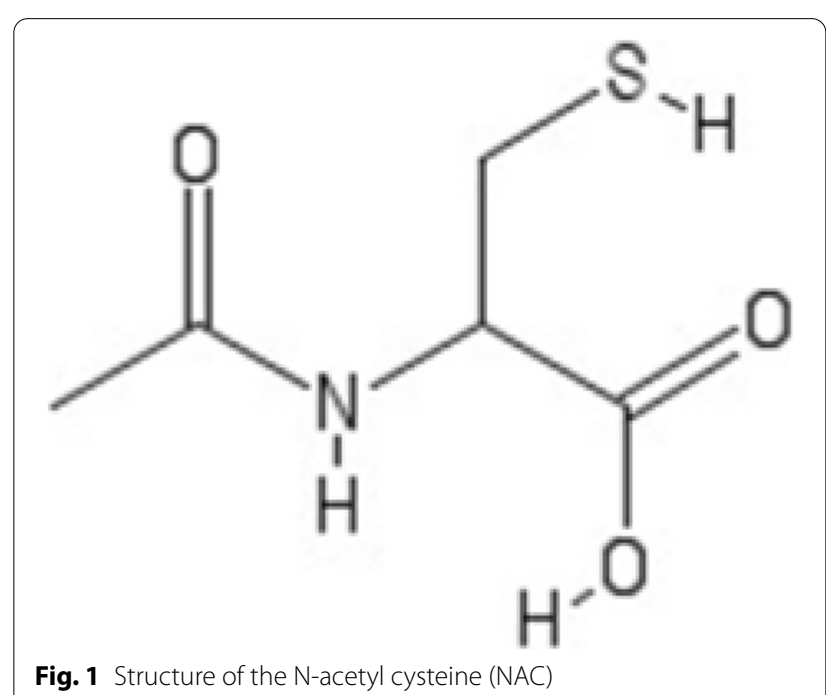


reducing the heavily cross-linked mucus, resulting in condensed mucous viscosity $[56,58]$.

\section{The antioxidant effect}

$\mathrm{N}$ - Acetyl cysteine is a significant antioxidant and a cytoprotective mediator that reloads intracellular glutathione. It has been shown to have a defensive role against cardiovascular complications [55]. This action is through complex methods by acting as a glutathione precursor and being a precursor of a thiol group [59, 60].

The antioxidant effect can be related to at least three different mechanisms

I. A direct antioxidant effect: NAC can act as a direct antioxidant or direct scavenger for many oxidant radicals such as " $\mathrm{NO}_{2}, \mathrm{OH}$, and $\mathrm{CO}_{3}$ " and nonradical oxidants such as hypochlorous $(\mathrm{HOCl})$ and related species which are oxidants formed from activated neutrophils and monocytes through the activity of myeloperoxidase (MPO) that are involved in the pathophysiology of some lung diseases [61].

II. An indirect antioxidant effect: as a result of NAC's capability to act as a cysteine precursor, in which it serves as a substrate for the synthesis of glutathione (GSH) in the body, thus preventing the damaging effects in some organs like; liver, skin, lung, and brain [62].

III. GSH is a direct antioxidant for a lot of antioxidant enzymes including glutathione (reductase, peroxidase, glyoxalases 1 and 2, peroxiredoxin, transferase) and (membrane-associated proteins in eicosanoid and glutathione metabolism) MAPEG [63]. NAC also augments the glutathione content of the tissues and tissue GSH-to-oxidized GSH ratio [59, 60].

IV. A breaking effect on disulfides and reserve ability of thiol pools, which regulates the redox state; it is the unique reducing effect of NAC. This releases free thiols, which have better antioxidant activity and enhance the GSH synthesis, besides reduced proteins, which have an important direct antioxidant activity in numerous cases, as for mercaptoalbumin. The reducing action of NAC also can explain its mucolytic activity in reducing heavily cross-linked mucus glycoproteins [57, 64].

\section{Anti-inflammatory effect}

NAC inhibits the inflammatory cytokines including; tumor necrosis factor-alpha (TNF $\alpha$ ), IL-1 $\beta$, and IL-6. In addition, it can reduce the activation of transcription factors NF- $\mathrm{kB}$ which is responsible for the initiation of inflammatory process and causes downregulation of IL-10 mRNA and protein expression in NAC-treated cells which cause further modification of the inflammatory cytokine profile $[56,65]$.

Rationale of the potential efficacy of $N$ acetyl cysteine in the management of COVID-19 NAC was described to reduce the manifestations of influenza-like illness in humans and administration of a dose of $100 \mathrm{mg} / \mathrm{kg}$ can contribute to the success of the management of contaminated cases with the 2009 pandemic H1N1 virus [66]. The following are the beneficial mechanisms of NAC in COVID-19

1. An anti-inflammatory effect is used in acute respiratory distress syndrome (ARDS) to protect cells from inflammation and apoptosis, so it may reduce the overall intensive care admission rate [67].

2. Antioxidant effect of NAC can potentially ameliorate COVID-19 induced oxidative stress complications as ARDS and multi-organ failure [68]. Also, the antioxidant effect of NAC can counteract the unfortunate antioxidant defense that present in patients with old age, smoking and chronic debilitating disorders, and may grave the outcome of COVID-19 due to the lack of endogenous glutathione [37, 38, 69]. proved that NAC increases the level and the activity of glutathione reductase (GR) enzyme, and an increased level of this enzyme can increase glutathione level in about $40 \%$ of COVID-19 cases.

3. Antiviral effects were supported by several studies that explaining its anti-viral activity against influenza A strains [70, 71]. It raises GSH levels which can diminish the viral load by inhibiting the viral replication, inhibits the production of pro-inflammatory molecules (CXCL8, CXCL10, CCL5 and interleukin-6 (IL-6)), and reduces the activation of transcription factors NF-kB [72].

4. NAC can ameliorate ribavirin therapeutic index, either by declining its toxicity or even allowing the use of a lower dose of the ribavirin, a previous report was conducted on mice illustrated that administration of NAC combined with antiviral therapy had a better response, both have a diverse mechanism of action that improves the outcome and reduce the severity of illness [71].

\section{NAC treatment regimen}

NAC is recommended to use in high doses $600-900 \mathrm{mg}$ twice daily in COVID -19 to decline the complications 
and to improve the outcome [68]. As NAC is considered a safe drug with low toxicity and mild side effects including nausea, vomiting, tachycardia, and pruritus, there is no fear to administrate it in high doses [55].

Lastly, Mohanty et al. [73] concluded that NAC has proven antioxidant activity which is useful in attenuating the immune activation and cytokine storm in animal and human studies. It is a safe, cost-effective, widely available drug, and its mechanism of action hypothetically suggests its potential role in the management of cytokine storm in COVID-19. However, with the limited evidence currently available, it would be imprudent to formulate any recommendation regarding the use of NAC in COVID-19. Any future recommendation regarding its use in this condition will depend on the outcome of the ongoing clinical trials. There are also found two case series related to the use of NAC in COVID-19 [74, 75].

\section{Naloxone and low-dose naltrexone (LDN) Naloxone}

Naloxone is an official primary antidote of opioid overdoes; it acts at the brain $\mu$-opioid receptor as a neutral competitive antagonist [76], Naloxone has great selectivity for the $\mu$ opioid receptor ([77] ), in addition to its ability to bind to kappa and sigma opioid receptors. Besides its effects against exogenous opioids, the activity further extends to the endogenous endorphins [78]. It is one of the components of the "coma cocktail" which is a part of empirical treatments to correct altered mental status of unknown cause [79]. It can be used in the newborn for respiratory depression reversal that occurs due to transplacentally acquired narcotics [80].

It was established that naloxone produces a favorable action on respiratory mechanics, pulmonary function test parameters, and oxygen metabolism of cases with respiratory failure, and it can considerably improve the general state of the body [81]. ChuiLi [82] reported that naloxone combined with the non-invasive ventilation can rapidly improve the clinical complaints and arterial blood gasses findings in respiratory failure associated with pulmonary encephalopathy. Newborns with respiratory failure also respond better with using naloxone in large doses, without any side-effects [83].

Ayres et al. [84] was the first one who explained the role of using naloxone in respiratory failure. Naloxone creates an increase in oxygen saturation in excess of the increase in ventilation, so better ventilation-perfusion matching is established in the acute illnesses with acute respiratory failure [84].

Chemically, Naloxone is a synthetic derivative of oxymorphone $(\mathrm{C} 19 \mathrm{H} 21 \mathrm{NO} 4)$ in which the $N$-allyl group replace $N$-methyl one [42]. There are numerous routes in which naloxone can be administered, either intravenously, intramuscularly, subcutaneously, and intranasally. Oral forms of the drug has rapid first-pass metabolism and thus do not provide the necessary efficacy resulting in extensive naloxone metabolism before blood stream access [85]. The recommended original dose of naloxone ranges from 0.04 to $0.4 \mathrm{mg}$ [86].

Naloxone had US Food and Drug Administration (FDA) approval in 1971 (off-patent 1985) as Narcan I.V. It is on the core list by WHO of the crucial medicines as it is regarded as an example of the ideal antidote [87]. Auto-injector naloxone has been approved by the US FDA for usage in 2014 (Edwards, [88]) as Evzio, and in November 2015, Narcan Nasal Spray became the first US FDA-approved non-injectable naloxone product for the treatment of opioid overdose [89].

Naloxone as a neutral antagonist, do not have risk for overdose [90] .In non-dependent opioids patients, naloxone has a high tolerability profile as opioid withdrawal is the most frequently reported adverse effect with symptoms of nausea, irritability, vomiting, and anxiety [91].

\section{Low dose naltrexone (LDN)}

Naltrexone has the highest $\mu$-opioid receptors affinity, like naloxone being pure opioid antagonist that was approved by FDA for the treatment of opioid addiction in 1984 [92]. It is comparable to the naloxone concerning the structure and the function, but with better oral bioavailability and a longer biologic half-life [93]. Chemically, naltrexone is 17-(cyclopropylmethyl)-4,5-epoxy-3,14-dihydroxymorphinan-6-one [94].

The term low-dose naltrexone (LDN) refers to doses about $1 / 10$ th the size of the dose used normally in opioid overdose; typically $4.5 \mathrm{mg}$ though a variable dose a limited milligrams below or above that communal value $(50 \mathrm{mg})$ $[95,96]$. In the contrary to higher doses of naltrexone, LDN cause increasing the endorphins release in the body through its action on the $\beta$-endorphin receptors [97].

Rationale of the potential efficacy of LDN in the management of COVID-19

1. LDN has the ability to reduce pro-inflammatory cytokines as it was found to be allied with a decline of plasma concentrations of transforming growth factor (TGF)- $\beta$ which belongs to a group of cytokines that is together called 'The super-family TGF- $\beta$, and also responsible for regulating epithelial cell differentiation, expansion, organization, motility, and apoptosis [98].

2. LDN has the capability to raise anti-inflammatory cytokines. It is established that COVID-19 cases were 
allied with increased level and activity of TGF- $\beta$ due to the virus-induced violent immune and inflammatory reactions with the dysregulation of the coagulation and fibrinolytic pathways that extremely stimulate the latent TGF- $\beta$ in the lungs and the blood of the contaminated cases [99]. COVID-19 contagion is linked with massive increase of neutrophil infiltration into the lungs where the neutrophils can release the stored TGF- $\beta$, being a strong chemokine-like molecule; so, it can engage more neutrophils into the lung resulting in a vicious cycle. LDN can ameliorate edema and fibrosis in the lungs of COVID-19 cases, due to activation of TGF- $\beta$ which is one of the known causes of lung fibrosis and as well as disturbances in the fluid homeostasis in the lung [100]; due to uncontrolled inflammatory reactions, "cytokine storm" ultimating in edema and fibrosis in the lungs in COVID19 cases [101].

3. LDN is an immune-modulator that decreases the number of TH1 cells and TH17 cells results in immune-balance with the regulation of cytokines release [36]. Among cytokines concerned in the storm allied with COVID-19 are those involved in T helper 17 (TH17) type responses as evidenced by the remarkably high number of TH17 cells in the peripheral blood of a case with severe COVID-19 contagion [35]. TH17 cells themselves produce IL-17, G-CS, IL-21, IL-22, IL-17 IL-1 $\beta$, IL-6, and TNF $\alpha$ interleukins. IL-17 has extensive pro-inflammatory properties on the induction of cytokine G-CS (responsible for recruitment of neutrophils) and IL-22 (which stimulates mucins, fibrinogen, anti-apoptotic proteins, and serum amyloid A) [102].

4. LDN is a modulating tool of the neuroimmune axis causing higher reactivity of immune cells mediated by transient increases in the opioid growth factor $[103,104]$ . The classical effect of naltrexone at low-dose range is the transient opioid receptor blockade resulting in upregulation of opioid signaling [105]. Experimental models guarantee the role of LDN in the upregulation of the endogenous opioid system through raising the levels of beta-endorphin and met-enkephalin (opioid growth factor) [106].

5. LDN is considered as "Enhancer of quality of life" due to its probable neuropsychological theoretical benefits [105] as upregulated endorphins have neuropsychological benefits arises from the well-reported relations between mu-opioid receptors and mesencephalon dopamine neurons $[103,107]$. The field of psychoneuroimmunology (PNI) illustrates the link between mood and immunity allowing mutual influences between the brain and the immune system $[108,109]$.
6. LDN may promote both the prevention and the management of viral disorders and bacterial contagions through being immune functions enhancer and especially the natural killer cell activity [110]. Cytokines as chemical messengers are made by immune cells that can be either increase or decrease the immune function. The body's capability to keep a balance between cytokines that promote inflammation and those that reduce it is responsible for the harmonization between the diverse responses of the immune system [111].

\section{The potential side effects of naloxone in the context of COVID-19}

A recent meta-analysis focused on probable troubles subsequent to naloxone management, precisely reviewing literature related to whether naloxone increased the risk of seizures after treatment of tramadol poisoning [112]. Furthermore, a recent study in 2017 stated on 2 unblinded randomized controlled articles comparing the frequency of adverse measures with either intranasal naloxone via a mucosal atomizer or intramuscular naloxone, involving anxiety and/or violence, nausea, vomiting, and headache [113].

\section{Deferoxamine (Desferal)}

Deferoxamine is an iron-chelating mediator used in the handling of acute iron poisoning and chronic iron overload. It belongs to heavy metal antagonists as it chalets iron by creating a stable complex which averts additional biochemical reactions of iron. It is available in vials for any form of injection.

Rationale of the potential efficiency of deferoxamine in the management of COVID-19

1. Decreasing the iron availability by deferoxamine causing decline of viral multiplication [114]. Furthermore, it is declared that iron overload is also implicated as a hazard element for rapid evolution of the illness [115].

2. Inhibiting the synthesis of DNA through inactivation of iron-dependent ribonucleotide reductase, thus altering the viral multiplication [116].

3. Reducing the development of free hydroxyl radicals [117]. Deferoxamine is a well-known antioxidant agent. High serum level of iron is allied with increased oxidative stress particularly in viralinfected cases $[118,119]$.

4. Ameliorating the cardiac injuries of severely ill COVID-19 cases throughout its antioxidant features [14]. 
5. Preventing the organ injury and reduce the fatality rate in a variety of experimental and clinical models of ischemia-reperfusion injury [120].

\section{Adverse effects}

- Local responses such as swelling and tenderness at the injection site
- Systemic reactions for example allergic reactions, arthralgia, fever, headache, myalgia, or asthma

- Digestive troubles as abdominal ache, nausea, vomiting, and diarrhea

- Cardiovascular reactions as tachycardia, shock, and hypotension

- Other adverse properties like blood dyspraxia, cramps in the leg, and some neurological disorders

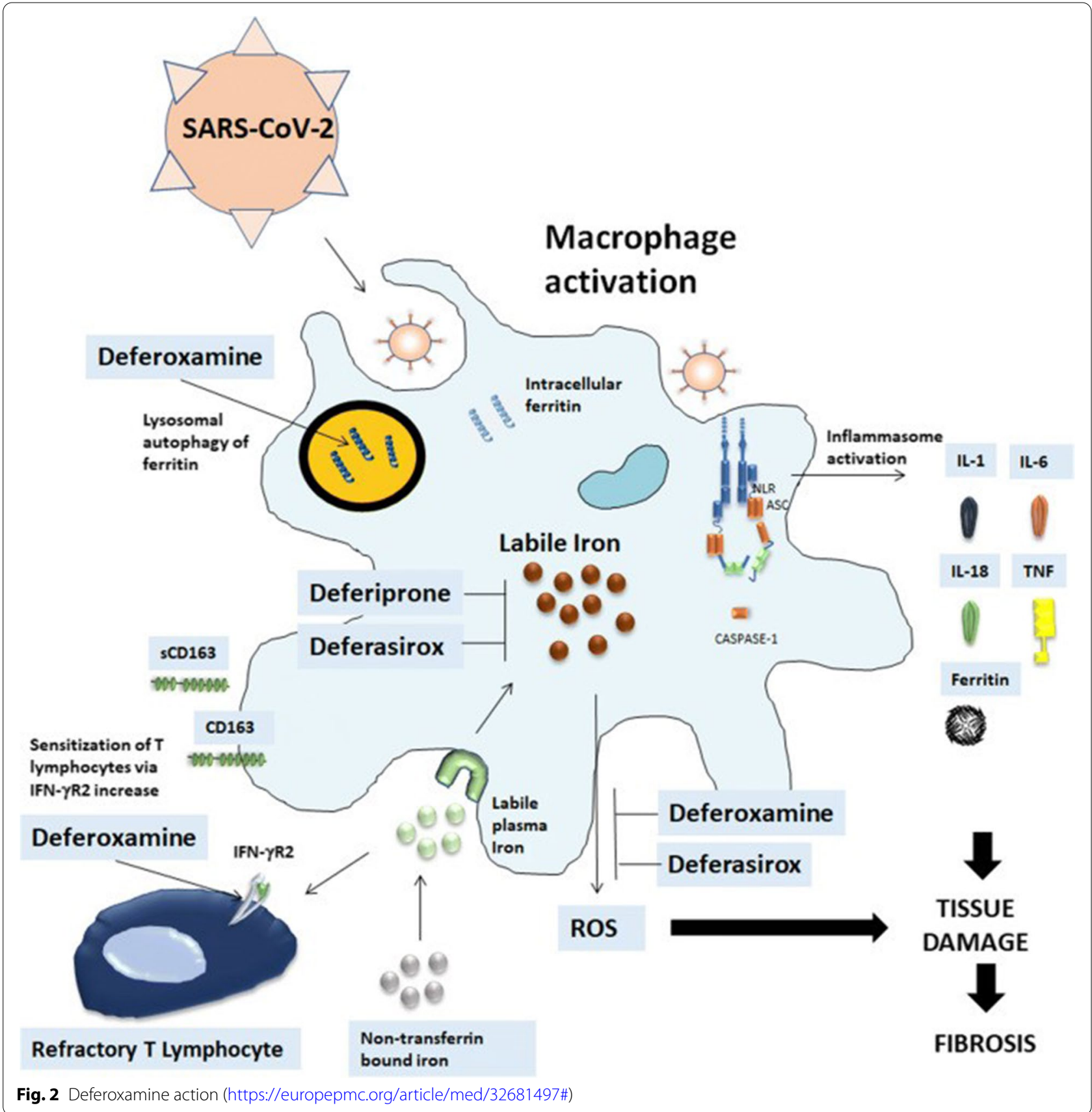


involving faintness, peripheral neuropathy, paresthesia, and encephalopathy

- Ocular and auditory dilemma

Desferal-iron complex is excreted predominantly throughout the kidney, so it is contraindicated in cases with severe renal troubles (Fig. 2).

\section{Conclusions}

- Deferoxamine is an iron-chelating agent. The use of deferoxamine seems to be of very limited benefit in selected patients in critical COVID-19 with vague mechanism.it needs to be validated especially that its adverse effects are multiple and may be fatal.

- Besides the antidotal action of naloxone and naltrexone as a pure opioid antagonist, naloxone may show some benefit but still there is limited evidence-based information about this and the authors didnot mention the potential side effects of the medication in the context of COVID-19. Maybe its use in critical or severe COVID may be beneficial but still this needs validation.

- Hyperbaric oxygen therapy (HBOT) is the most powerful oxygen therapy known. It can solve the problem of hypoxemia more effectively than normal pressure oxygen therapy with either high flow oxygen inhalation or mechanical ventilation as well as its role in improving circulation, alteration of coagulation cascade, and immune suppressive effect. Moreover, it seems that this is a rather expensive modality of treatment for very selected patients that is not available in most centers and requires special expertise. Obviously, the pandemic was very widespread rendering the use of this modality tremendously limited.

- N. acetyl cysteine is considered an essential drug for a healthy life, a safe drug with mild side effects. There is so limited evidence-based proof for the benefit of $\mathrm{N}$-acetyl cysteine in treatment of mild and moderate cases of COVID-19 and although side effects are not serious but they really upset the patient especially the GIT symptoms.

- Finally, further large clinical trials are needed to study the efficacy of these agents.

\section{Abbreviations}

SARS-CoV: Severe acute respiratory syndrome coronavirus; MERS-CoV: Middle East respiratory syndrome coronavirus; COVID-19: Coronavirus disease 2019; WHO: World Health Organization; nCoV-19: Novel coronavirus; HCoV-229E: Human coronavirus 229E; HCoV-OC43: Human coronavirus OC43; SARS: Severe acute respiratory syndrome; ICU: Intensive care unit; HBOT: Hyperbaric
}

oxygen therapy; TNFa: Tumor necrosis factor alpha; TLR: Toll-like receptor; NFKB: Nuclear factor KB; PE: Pulmonary embolism; IHBO: Intermittent hyperbaric oxygen; HBO: Hyperbaric oxygen; BBB: Blood-brain barrier; SO2: Oxygen saturation; NAC: N-acetylcysteine; NO2: Nitrogen dioxide; $\mathrm{OH}$ : Hydroxyl radical; CO3: Carbonate radical anion; HOCl: Hypochlorous acid; GSH: Glutathione; IL10: Interleukin 10; ARDS: Acute respiratory distress syndrome; CXCL8: Chemokine (C-X-C motif) ligand 8; CXCL10: C-X-C motif chemokine 10; CCL5: Chemokine (C-C motif) ligand 5; LDN: Low-dose naltrexone; US: United States; FDA: Food and Drug Administration; TGF: Transforming growth factor; TH: T helper cell; G-CS: Granulocyte colony stimulating.

\section{Acknowledgements \\ None}

\section{Authors' contributions}

All authors substantially contributed to the conception, design, analysis, and interpretation of data, checking and approving the final version of the manuscript, and agree to be accountable for its contents.

\section{Funding}

This review is written, analyzed, and designed by its authors and required no substantial funding to be stated.

\section{Availability of data and materials}

Data are available.

\section{Declarations}

Ethics approval and consent to participate

Not applicable.

\section{Consent for publication}

Not applicable.

\section{Competing interests}

The authors declare that they have no competing interests.

\section{Author details}

${ }^{1}$ Forensic Medicine and Clinical Toxicology Department, Faculty of Medicine, Assiut University, Asyut, Egypt. ${ }^{2}$ Chest Department, Faculty of Medicine, Aswan University, Aswan, Egypt. ${ }^{3}$ Forensic Medicine and Clinical Toxicology Department, Faculty of Medicine, Ain Shams University, Cairo, Egypt.

Received: 25 August 2021 Accepted: 7 December 2021

Published online: 20 January 2022

\section{References}

1. Holshue ML, DeBolt C, Lindquist S, Lofy KH, Wiesman J, Bruce H et al (2020) First case of 2019 novel coronavirus in the United States. N Engl J Med 382:929-936

2. Remuzzi A, Remuzzi G (2020) COVID-19 and Italy: what next? Lancet 395:1225-1228

3. Stoecklin SB, Rolland P, Silue Y, Mailles A, Campese C, Simondon A et al (2020) First cases of coronavirus disease 2019 (COVID-19) in France: surveillance, investigations and control measures, January 2020. Eurosurveillance 25(6):2000094

4. Cheng MP, Papenburg J, Desjardins M, Kanjilal S, Quach C, Libman M et al (2020) Diagnostic testing for severe acute respiratory syndrome-related coronavirus-2: a narrative review. Ann Intern Med 172(11):726-34

5. Liu J, Liao X, Qian S, Yuan J, Wang F, Liu Y et al (2020a) Community transmission of severe acute respiratory syndrome coronavirus 2, Shenzhen, China, 2020. Emerg Infect Dis 26(6):1320.

6. Liu J, Zheng X, Tong Q, Li W, Wang B, Sutter K et al (2020b) Overlapping and discrete aspects of the pathology and pathogenesis of the emerging human pathogenic coronaviruses SARS-CoV, MERS-CoV, and 2019-nCoV. J Med Virol 92(5):491-494 
7. El-Aziz A, Kasem SM, Ali MF, Mohamed SM, El Shehaby DM (2021) Rational of invertebrates and herbs extracts for protection and management of coronavirus (COVID 19). Egyptian Academic Journal of Biological Sciences, G. Microbiology 13(1):29-47

8. Wu D, Wu T, Liu Q, Yang Z (2020) The SARS-CoV-2 outbreak: what we know. Int J Infect Dis 94:44-48

9. Lake MA (2020) What we know so far: COVID-19 current clinical knowledge and research. Clin Med 20(2):124

10. Hughes C, Nichols T, Pike M, Subbe C, Elghenzai S (2020) Cerebral venous sinus thrombosis as a presentation of COVID-19. Eur J Case Rep Int Med 7(5)

11. Li G, Fan Y, Lai Y, Han T, Li Z, Zhou P et al (2020a) Coronavirus infections and immune responses. J Med Virol 92(4):424-432

12. Li H, Wang Y, Xu J, Cao B (2020b) Potential antiviral therapeutics for 2019 Novel Coronavirus. Zhonghua jie he he hu xi za zhi= Zhonghua jiehe he huxi zazhi=Chin J Tuberculosis Respir Dis 43:E002-E002

13. Wang D, Hu B, Hu C, Zhu F, Liu X, Zhang J et al (2020a) Clinical characteristics of 138 hospitalized patients with 2019 novel coronavirusinfected pneumonia in Wuhan, China. Jama 323(11):1061-1069

14. Wang J-Z, Zhang R-Y, Bai J (2020b) An anti-oxidative therapy for ameliorating cardiac injuries of critically ill COVID-19-infected patients. Int J Cardiol 312:137

15. Adedeji AO, Severson W, Jonsson C, Singh K, Weiss SR, Sarafianos SG (2013) Novel inhibitors of severe acute respiratory syndrome coronavirus entry that act by three distinct mechanisms. J Virol 87(14):8017-8028

16. Luk HK, Li X, Fung J, Lau SK, Woo PC (2019) Molecular epidemiology, evolution and phylogeny of SARS coronavirus. Infect Genet Evol 71:21-30

17. Chen X, Chughtai AA, Dyda A, MacIntyre CR (2017) Comparative epidemiology of Middle East respiratory syndrome coronavirus (MERS-CoV) in Saudi Arabia and South Korea. Emerg Microbes Infect 6(1):1-6

18. Yu F, Yan L, Wang N, Yang S, Wang L, Tang Y et al (2020) Quantitative detection and viral load analysis of SARS-CoV-2 in infected patients. Clin Infect Dis 71(15):793-8

19. Li F (2016) Structure, function, and evolution of coronavirus spike proteins. Annu Rev Virol 3:237-261

20. Neumann H, Neumann-Staubitz P (2010) Synthetic biology approaches in drug discovery and pharmaceutical biotechnology. Appl Microbiol Biotechnol 87(1):75-86

21. Yang X, Yu Y, Xu J, Shu H, Liu H, Wu Y et al (2020) Clinical course and outcomes of critically ill patients with SARS-CoV-2 pneumonia in Wuhan, China: a single-centered, retrospective, observational study. Lancet Respir Med 395(10223):497-506

22. Pyrc K, Berkhout B, Van Der Hoek L (2007) Identification of new human coronaviruses. Expert Rev Anti Infect Ther 5(2):245-253

23. Ong SWX, Tan YK, Chia PY, Lee TH, Ng OT, Wong MSY, Marimuthu K (2020) Air, surface environmental, and personal protective equipment contamination by severe acute respiratory syndrome coronavirus 2 (SARS-CoV-2) from a symptomatic patient. Jama 323(16):1610-1612

24. Morawska L, Johnson G, Ristovski Z, Hargreaves M, Mengersen K, Corbett $S$ et al (2009) Size distribution and sites of origin of droplets expelled from the human respiratory tract during expiratory activities. J Aerosol Sci 40(3):256-269

25. Zhang J, Xie B, Hashimoto K (2020a) Current status of potential therapeutic candidates for the COVID-19 crisis. Brain Behav Immun 87:59-73

26. Zhang Y, Chen C, Zhu S, Shu C, Wang D, Song J et al (2020b) Isolation of 2019-nCoV from a stool specimen of a laboratory-confirmed case of the coronavirus disease 2019 (COVID-19). China CDC Weekly 2(8):123-124

27. Yuki K, Fujiogi M, Koutsogiannaki S (2020) COVID-19 pathophysiology: a review. Clin Immunol 108427

28. Sanders JM, Monogue ML, Jodlowski TZ, Cutrell JB (2020) Pharmacologic treatments for coronavirus disease 2019 (COVID-19): a review. Jama. 323(18):1824-1836

29. Lu L, Liu Q, Du L, Jiang S (2013) Middle East respiratory syndrome coronavirus (MERS-COV): challenges in identifying its source and controlling its spread. Microbes Infect 15(8-9):625-629
30. Lai KN, Leung JC, Metz CN, Lai FM, Bucala R, Lan HY (2003) Role for macrophage migration inhibitory factor in acute respiratory distress syndrome. J Pathol 199(4):496-508

31. Brent J, Burkhart K, Dargan P, Hatten B, Megarbane B, Palmer R, White J (2017) Critical care toxicology: diagnosis and management of the critically poisoned patient. Germany: Springer

32. Goldfrank LR, Flomenbaum NE, Lewin NA, Howland MA, Hoffman RS, Nelson L (2015) Goldfrank's toxicologic emergencies. McGraw-Hill, New York, pp 2545-2557

33. Kirby JP, Snyder J, Schuerer DJ, Peters JS, Bochicchio GV (2019) Essentials of hyperbaric oxygen therapy: 2019 review. Mo Med 116(3):176

34. Harch PG (2020) Hyperbaric oxygen treatment of novel coronavirus (COVID-19) respiratory failure. Med Gas Res 10(2):61

35. Xu Z, Shi L, Wang Y, Zhang J, Huang L, Zhang C et al (2020a) Pathological findings of COVID-19 associated with acute respiratory distress syndrome. Lancet Respir Med 8(4):420-422

36. Xu N, Wang Y, Zhao S, Jiao T, Xue H, Shan F, Zhang N (2020b) Naltrexone (NTX) relieves inflammation in the collagen-induced-arthritis (CIA) rat models through regulating TLR4/NFKB signaling pathway. Int Immunopharmacol 79:106056

37. Chen N, Zhou M, Dong X, Qu J, Gong F, Han Y et al (2020a) Epidemiological and clinical characteristics of 99 cases of 2019 novel coronavirus pneumonia in Wuhan, China: a descriptive study. Lancet. 395(10223):7

38. Chen R, Zhong X, Tang Y, Liang Y, Li B, Tao X, Liao C (2020b) The outcomes of hyperbaric oxygen therapy to severe and critically ill patients with COVID-19 pneumonia

39. Majeed A, Shajar MA (2020) Is hemoglobin the missing link in the pathogenesis of COVID-19? Anaesthesia, Pain Intensive Care 24(1):9-12

40. Geier MR, Geier DA (2020) Respiratory conditions in coronavirus disease 2019 (COVID-19): important considerations regarding novel treatment strategies to reduce mortality. Med Hypotheses 140:109760

41. Zhong X, Tao X, T. Y. e. al. (2020) Effect of hyperbaric oxygen therapy to treat hypoxia in severe novel coronavirus pneumonia patients: first case report. Chin J Nauti and Hyperb Med 27:1

42. Al-Waili NS, Butler GJ (2006) Effects of hyperbaric oxygen on inflammatory response to wound and trauma: possible mechanism of action. Scientific World Journal 6:425-441

43. Benson R, Minter L, Osborne B, Granowitz E (2003) Hyperbaric oxygen inhibits stimulus-induced proinflammatory cytokine synthesis by human blood-derived monocyte-macrophages. Clin Exp Immunol 134(1):57-62

44. Conti P, Ronconi G, Caraffa A, Gallenga C, Ross R, Frydas I, Kritas S (2020) Induction of pro-inflammatory cytokines (IL-1 and IL-6) and lung inflammation by coronavirus-19 (COVI-19 or SARS-CoV-2): anti-inflammatory strategies. J Biol Regul Homeost Agents 34(2):1

45. Meng X-E, Zhang Y, Li N, Fan D-F, Yang C, Li H et al (2016) Hyperbaric oxygen alleviates secondary brain injury after trauma through inhibition of TLR4/NF-KB signaling pathway. Med Sci Monitor: Int Med J Exp Clin Res 22:284

46. Wu Z-S, Lo J-J, Wu S-H, Wang C-Z, Chen R-F, Lee S-S et al (2018) Early hyperbaric oxygen treatment attenuates burn-induced neuroinflammation by inhibiting the galectin-3-dependent toll-like receptor-4 pathway in a rat model. Int J Mol Sci 19(8):2195

47. Prockop LD, Chichkova RI (2007) Carbon monoxide intoxication: an updated review. J Neurol Sci 262(1-2):122-130

48. Ustad F, Ali F, U. T. e. al. (2012) Uses of hyperbaric oxygen therapy: a review. JEMDS 1(5):892-906

49. Imperatore F, Cuzzocrea S, De Lucia D, Sessa M, Rinaldi B, Capuano A et al (2006) Hyperbaric oxygen therapy prevents coagulation disorders in an experimental model of multiple organ failure syndrome. Intensive Care Med 32(11):1881-1888

50. Jain K (2017) Role of hyperbaric oxygenation in the management of stroke. Textbook of Hyperbaric Medicine, 6th edn. Springer, Cham, pp 237-286

51. Klok F, Kruip M, Van der Meer N, Arbous M, Gommers D, Kant K et al (2020) Incidence of thrombotic complications in critically ill ICU patients with COVID-19. Thromb Res 191:145-7

52. Oliaei S, SeyedAlinaghi S, Mehrtak M, Karimi A, Noori T, Mirzapour P, Shojaei A, MohsseniPour M, Mirghaderi SP, Alilou S, Shobeiri P (2021) 
The effects of hyperbaric oxygen therapy (HBOT) on coronavirus disease-2019 (COVID-19): a systematic review. Eur J Med Res 26(1):1-2

53. AAMHEI (2020). "The potential role of hyperbaric oxygen therapy (HBOT) in the care of patients with COVID-19." from https://www. aamhei.com/en/covid-19-link-library/.

54. Heyboer M III, Sharma D, Santiago W, McCulloch N (2017) Hyperbaric oxygen therapy: side effects defined and quantified. Adv Wound Care 6(6):210-224

55. Samuni Y, Goldstein S, Dean OM, Berk M (2013) The chemistry and biological activities of $\mathrm{N}$-acetylcysteine. Biochim Biophys Acta (BBA)General Subjects 1830(8):4117-4129

56. Tardiolo G, Bramanti P, Mazzon E (2018) Overview on the effects of $\mathrm{N}$-acetylcysteine in neurodegenerative diseases. Molecules 23(12):3305

57. Aldini G, Altomare A, Baron G, Vistoli G, Carini M, Borsani L, Sergio F (2018) N-Acetylcysteine as an antioxidant and disulphide breaking agent: the reasons why. Free Radic Res 52(7):751-762

58. Murgia X, Loretz B, Hartwig O, Hittinger M, Lehr C-M (2018) The role of mucus on drug transport and its potential to affect therapeutic outcomes. Adv Drug Deliv Rev 124:82-97

59. Zhang H, Su W, Ying Z, Chen Y, Zhou L, Li Y et al (2018a) N-acetylcysteine attenuates intrauterine growth retardation-induced hepatic damage in suckling piglets by improving glutathione synthesis and cellular homeostasis. Eur J Nutr 57(1):327-338

60. Zhang L, Xu S, Huang Q, Xu H (2018b) N-acetylcysteine attenuates the cuprizone-induced behavioral changes and oligodendrocyte loss in male C57BL/7 mice via its anti-inflammation actions. J Neurosci Res 96(5):803-816

61. O'Donnell C, Newbold P, White P, Thong B, Stone H, Stockley RA (2010) 3-Chlorotyrosine in sputum of COPD patients: relationship with airway inflammation. COPD: J Chron Obstruct Pulmon Dis 7(6):411-417

62. El Shehaby DM, El-Mahdy Rl, Ahmed AM, Hosny A, Abd el-Rady, N. M. (2020) Neurobehavioral, testicular and erectile impairments of chronic ketamine administration: pathogenesis and ameliorating effect of N-acetyl cysteine. Reprod Toxicol 96:57-66

63. Deponte M (2013) Glutathione catalysis and the reaction mechanisms of glutathione-dependent enzymes. Biochim Biophys Acta (BBA)General Subjects 1830(5):3217-3266

64. Nagy P (2013) Kinetics and mechanisms of thiol-disulfide exchange covering direct substitution and thiol oxidation-mediated pathways. Antioxid Redox Signal 18(13):1623-1641

65. Palacio J, Markert U, Martínez P (2011) Anti-inflammatory properties of $\mathrm{N}$-acetylcysteine on lipopolysaccharide-activated macrophages. Inflamm Res 60(7):695-704

66. Lai KY, Ng WY, Osburga Chan PK, Wong KF, Cheng F (2010) High-dose $\mathrm{N}$-acetylcysteine therapy for novel H1N1 influenza pneumonia. Ann Intern Med 152(10):687-688

67. Lu X, Ma Y, He J, Li Y, Zhu H, Yu X (2019) N-acetylcysteine for adults with acute respiratory distress syndrome: a meta-analysis of randomized controlled trials. Hong Kong J Emerg Med 26(5):288-298

68. McCarty MF, DiNicolantonio JJ (2020) Nutraceuticals have potential for boosting the type 1 interferon response to RNA viruses including influenza and coronavirus. Prog Cardiovasc Dis 63(3):383

69. Polonikov A (2020) Endogenous deficiency of glutathione as the most likely cause of serious manifestations and death in COVID-19 patients. ACS Infect Dis 6(7):1558-62

70. Geiler J, Michaelis M, Naczk P, Leutz A, Langer K, Doerr H-W, Cinatl J Jr (2010) N-acetyl-L-cysteine (NAC) inhibits virus replication and expression of pro-inflammatory molecules in A549 cells infected with highly pathogenic H5N1 influenza A virus. Biochem Pharmacol 79(3):413-420

71. Ghezzi P, Ungheri D (2004) Synergistic combinationof N-acetylcysteine and ribavirin to protect from lethal influenza viral infection in a mouse model. Int J Immunopathol Pharmacol 17(1):99-102

72. Van Hecke O, Lee J (2020) N-acetylcysteine: a rapid review of the evidence for effectiveness in treating COVID-19. Centre for EvidenceBased Medicine, Oxford University

73. Mohanty RR, Padhy BM, Das S, Meher BR (2021) Therapeutic potential of $\mathrm{N}$-acetyl cysteine (NAC) in preventing cytokine storm in COVID-19: review of current evidence. Eur Rev Med Pharmacol Sci 25(6):2802-2807

74. Horowitz Rl, Freeman PR, Bruzzese J (2020) Efficacy of glutathione therapy in relieving dyspnea associated with COVID-19 pneumonia: a report of 2 cases. Respir Med Case Rep 30:101063
75. Ibrahim H, Perl A, Smith D, Lewis T, Kon Z, Goldenberg R, Yarta K, Staniloae C, Williams M (2020) Therapeutic blockade of inflammation in severe COVID-19 infection with intravenous N-acetylcysteine. Clin Immunol 219

76. Hasegawa K, Brown DF, Tsugawa Y, Camargo CA Jr (2014) Epidemiology of emergency department visits for opioid overdose: a populationbased study. Mayo Clinic Proceedings, 89(4):462-471. Elsevier

77. Moon JM, Chun BJ (2011) Fentanyl intoxication caused by abuse of transdermal fentanyl. J Emerg Med 40(1):37-40

78. Kaufman DM, Geyer HL, Milstein MJ (2012) Kaufman's Clinical Neurology for Psychiatrists E-Book. Elsevier Health Sciences

79. Dart RC, Borron SW, Caravati EM, Cobaugh DJ, Curry SC, Falk JL, Goldfrank L, Gorman SE, Groft S, Heard K (2009) Expert consensus guidelines for stocking of antidotes in hospitals that provide emergency care. Ann Emerg Med 54(3):386-394. e381

80. McGuire W, Fowlie P (2003) Naloxone for narcotic exposed newborn infants: systematic review. Arch Dis Child Fetal Neonatal Ed 88(4):F308-F311

81. Xiang-wei H (2013) Influence of naloxone on respiratory mechanics, pulmonary function parameters and oxygen metabolism in patients with chronic obstructive pulmonary disease and respiratory failure [J]. J Hainan Med Univ 3

82. ChuiLi Z (2011) The effect of BiPAP union naloxone in treatment of type respiratory failure complicated with pulmonary encephalopathy [J]. Chin J Med Guide 9

83. Kong D, Wang X, Ren J (2001) Efficacy of naloxone in treatment of respiratory failure in newborn infants [J]. J Pediatr Pharm 4

84. Ayres J, Rees J, Lee T, Cochrane G (1982) Intravenous naloxone in acute respiratory failure. Br Med J (Clin Res) 284(6320):927-928

85. Coffin PO, Sullivan SD (2013) Cost-effectiveness of distributing naloxone to heroin users for lay overdose reversal. Ann Intern Med 158(1):1-9

86. Lavonas EJ, Drennan IR, Gabrielli A, Heffner AC, Hoyte CO, Orkin AM, Sawyer KN, Donnino MW (2015) Part 10: special circumstances of resuscitation: 2015 American Heart Association guidelines update for cardiopulmonary resuscitation and emergency cardiovascular care. Circulation 132(18_suppl_2):S501-S518

87. Sivilotti ML (2016) Flumazenil, naloxone and the 'coma cocktail'. Br J Clin Pharmacol 81(3):428-436

88. Edwards ET, Edwards ES, Davis E, Mulcare M, Wiklund M, Kelley G (2015) Comparative usability study of a novel auto-injector and an intranasal system for naloxone delivery. Pain Ther 4(1):89-105

89. Krieter P, Chiang N, Gyaw S, Skolnick P, Crystal R, Keegan F, Aker J, Beck M, Harris J (2016) Pharmacokinetic properties and human use characteristics of an FDA-approved intranasal naloxone product for the treatment of opioid overdose. The Journal of Clinical Pharmacology 56(10):1243-1253

90. Pellegrini E (2016) Analysis of increased public access to naloxone as a method to control the recent fentanyl epidemic. Boston University

91. Boyer EW (2012) Management of opioid analgesic overdose. N Engl J Med 367(2):146-155

92. Abuse S (2009) Mental Health Services Administration (SAMHSA). Incorporating alcohol pharmacotherapies into medical practice. Center for Substance Abuse Treatment, Rockville

93. Younger J, Parkitny L, McLain D (2014) The use of low-dose naltrexone (LDN) as a novel anti-inflammatory treatment for chronic pain. Clin Rheumatol 33(4):451-459

94. Toljan K, Vrooman B (2018) Low-dose naltrexone (LDN) —review of therapeutic utilization. Med Sci 6(4):82

95. Cree BA, Kornyeyeva E, Goodin DS (2010) Pilot trial of low-dose naltrexone and quality of life in multiple sclerosis. Ann Neurol 68(2):145-150

96. Smith JP, Bingaman SI, Ruggiero F, Mauger DT, Mukherjee A, McGovern CO, Zagon IS (2011) Therapy with the opioid antagonist naltrexone promotes mucosal healing in active Crohn's disease: a randomized placebo-controlled trial. Dig Dis Sci 56(7):2088-2097

97. Schwaiger $\mathrm{T}(2018)$ The uses of low-dose naltrexone in clinical practice; potential benefits for a wide range of conditions. Nat Med J 10(4) [https://www.naturalmedicinejournal.com/journal/2018-04/uses-lowdose-naltrexoneclinical-practice].

98. Chin D, Boyle GM, Parsons PG, Coman WB (2004) What is transforming growth factor-beta (TGF- $\beta$ )? Br J Plast Surg 57(3):215-221

99. Parkitny L, Younger J (2017) Reduced pro-inflammatory cytokines after eight weeks of low-dose naltrexone for fibromyalgia. Biomedicines 5(2):16 
100. Tatler AL, Jenkins G (2012) TGF- $\beta$ activation and lung fibrosis. Proc Am Thorac Soc 9(3):130-136

101. Felsenstein S, Herbert JA, McNamara PS, Hedrich CM (2020) COVID19: immunology and treatment options. Clin Immunol (Orlando, Fla) 215:108448-108448

102. Zenewicz LA (2018) IL-22: There is a gap in our knowledge. ImmunoHorizons 2(6): 198-207

103. Lutz P-E, Kieffer BL (2013) Opioid receptors: distinct roles in mood disorders. Trends Neurosci 36(3):195-206

104. McCusker RH, Kelley KW (2013) Immune-neural connections: how the immune system's response to infectious agents influences behavior. J Exp Biol 216(1):84-98

105. Brown N, Panksepp J (2009) Low-dose naltrexone for disease prevention and quality of life. Med Hypotheses 72(3):333-337

106. Rahn KA, McLaughlin PJ, Zagon IS (2011) Prevention and diminished expression of experimental autoimmune encephalomyelitis by low dose naltrexone (LDN) or opioid growth factor (OGF) for an extended period: Therapeutic implications for multiple sclerosis. Brain Res 1381:243-253

107. Alcaro A, Huber R, Panksepp J (2007) Behavioral functions of the mesolimbic dopaminergic system: an affective neuroethological perspective. Brain Res Rev 56(2):283-321

108. Gruzelier J (2002) A review of the impact of hypnosis, relaxation, guided imagery and individual differences on aspects of immunity and health. Stress 5(2):147-163

109. Solomon GF, Segerstrom SC, Grohr P, Kemeny M, Fahey J (1997) Shaking up immunity: psychological and immunologic changes after a natural disaster. Psychosom Med 59(2):114-127

110. Boyadjieva NI, Chaturvedi K, Poplawski MM, Sarkar DK (2004) Opioid antagonist naltrexone disrupts feedback interaction between $\mu$ and $\delta$ opioid receptors in splenocytes to prevent alcohol inhibition of NK cell function. J Immunol 173(1):42-49

111. Zhang J-M, An J (2007) Cytokines, inflammation and pain. Int Anesthesiol Clin 45(2):27

112. Zhang JM, An J (2007) Cytokines, inflammation and pain. International anesthesiology clinics 45(2):27

113. Peprah K, Severn M (2020) Intranasal and intramuscular naloxone for opioid overdose in the pre-hospital setting: a review of comparative clinical and cost-effectiveness, and guidelines

114. Georgiou NA, van der Bruggen T, Oudshoorn M, Nottet HS, Marx JJ, van Asbeck BS (2000) Inhibition of human immunodeficiency virus type 1 replication in human mononuclear blood cells by the iron chelators deferoxamine, deferiprone, and bleomycin. J Infect Dis 181(2):484-490

115. Chang H-C, Bayeva M, Taiwo B, Palella FJ Jr, Hope TJ, Ardehali H (2015) High cellular iron levels are associated with increased HIV infection and replication. AIDS Res Hum Retroviruses 31(3):305-312

116. Hoffbrand A, Ganeshaguru K, Hooton J, Tattersall M (1976) Effect of iron deficiency and desferrioxamine on DNA synthesis in human cells. Br J Haematol 33(4):517-526

117. Basaran UN, Ayvaz S, Aksu B, Karaca T, Cemek M, Karaboga I et al (2013) Desferrioxamine reduces oxidative stress in the lung contusion. Scientific World J 2013

118. Ji C, Kaplowitz N (2004) Hyperhomocysteinemia, endoplasmic reticulum stress, and alcoholic liver injury. World J Gastroenterol: WJG 10(12):1699

119. Loffredo L, Martino F, Zicari AM, Carnevale R, Battaglia S, Martino E et al (2019) Enhanced NOX-2 derived oxidative stress in offspring of patients with early myocardial infarction. Int J Cardiol 293:56-59

120. Vulcano M, Meiss RP, Isturiz M, n. A. (2000) Deferoxamine reduces tissue injury and lethality in LPS-treated mice. Int J Immunopharmacol 22(8):635-644

\section{Publisher's Note}

Springer Nature remains neutral with regard to jurisdictional claims in published maps and institutional affiliations.

\section{Submit your manuscript to a SpringerOpen ${ }^{\circ}$ journal and benefit from:}

- Convenient online submission

- Rigorous peer review

- Open access: articles freely available online

- High visibility within the field

- Retaining the copyright to your article

Submit your next manuscript at $\boldsymbol{\nabla}$ springeropen.com 